\title{
Quality in nursing home care: whose responsibility?
}

Long term care for elderly people in the United Kingdom is increasingly provided by nursing homes in the independent sector. Between 1983 and 1994 the number of National Health Service (NHS) continuing care beds fell from 55600 to 37500 and the number of nursing home beds rose from 18200 to $148500 .^{1}$ With an estimated one in four people over 85 currently receiving institutional care ${ }^{1}$ and projections that the number of people over 85 will more than double between now and 2041, it is likely that the number of nursing home beds will continue to rise. The history of long term institutional care is not a happy one ${ }^{3}$ and it is one that "Care in the Community" ${ }^{4}$ was specifically designed to rectify. It is therefore sad to see the Alzheimer's Disease Society reporting that in a recent survey of 1400 carers, one in 10 thought that their relatives had been mistreated in residential or nursing homes. ${ }^{5}$

Mistreatment is a fundamental failure that may be the result of failing to address current concerns about nursing home care: difficulty of monitoring and delivering quality through contracts, ${ }^{6}$ the conflict between quality and tight budgets, ${ }^{6}$ poor placement and review procedures, ${ }^{6}$ inappropriate prescribing, ${ }^{7}$ cost and work shifting between health and social services and between primary and secondary care,${ }^{6}$ and retreats by geriatricians into acute medicine and by general practitioners into core services. ${ }^{8}$ The end result of all of this is that nursing homes are often left considering themselves unsupported, undervalued, and squeezed by the market.

It is therefore good to see two articles in this volume $e^{910}$ which specifically consider the issue of quality in long term care for older people. Both papers, which evaluate the use of quality review packages (continuous assessment review and evaluation (CARE) and inside quality assurance (IQA)) in nursing homes, have some important messages. Developing the packages and identifying indicators of high quality long term care seems to be relatively straightforward. Implementing the process is more difficult. Both studies selected well motivated homes but one study reports a clear misunderstanding about the nature of audit and in the other, participation by staff varied from 1 to 10 with a mean of 3.9. A recent study in a defined geographical area which invited 37 nursing homes to take part in audit studies of their choice supported by a facilitator, only recruited 16 participants and three of this group failed to undertake any audit. ${ }^{11}$ This variable pattern of participation at the level of both homes and staff suggests that there is a need to develop more effective methods of marketing quality review, possibly through educational and developmental approaches.

Interesting issues are also raised about leadership within homes, the relation between owners and professional staff, and the need to value the poorly paid quasidomestic care workers who are key determinants of residential quality of life. Despite some initial difficulty in engaging with the homes, both studies show encouraging improvements in documentation of policies and in processes of care for residents. Importantly, once staff embarked on the audit they both enjoyed and recognised the value of what they were doing. The evidence from these two studies is that the process works and that the CARE scheme and IQA are valuable tools for quality assurance. The authors suggest some modifications to the approach and the paper by Dickinson and Brocklehurst makes a plea for commission- ers of long term care to use incentives so that providers create "a virtuous cycle of improvement". 9

This last point raises a serious issue about accountability and responsibility for quality long term care. The Registered Homes Act, $1984^{12}$ gives Health Authorities responsibility for regulating nursing homes although contracts remain the responsibility of social services. Authorities discharge this responsibility through the appointment of inspectors who sometimes but not always work in joint inspection units with social services inspectors who have responsibility under the Act for residential care. The legislation itself provides little guidance on what constitutes good quality care. Phrases such as "adequate" are applied to such issues as numbers of staff and storage of medication with no indication of what constitutes adequacy. Interpretation is therefore left to registration officers and their inspectors. Predictably and appropriately this has led to a focus on safety and minimum standards but a recent report expressed concern about the ability of inspectors to discharge this responsibility because of their mounting workload. ${ }^{6}$ Concerns have also been expressed that a minimum standards approach has a limited role in quality improvement. There is also a conflict between an external monitoring approach and evidence that suggests that an internal enabling approach focused on education and development is more effective in producing quality improvement. ${ }^{13}$

Another approach to quality is for commissioners to include quality specifications in contracts. Experience of this in the health services, which is longer and more structured than the experiences of the social services, is not particularly encouraging. A recent study reports that although quality specifications within contracts are common they are usually too non-specific to achieve desired quality goals and that their use is holding back a more fundamental debate on how to create effective management of quality improvement through the interaction between purchasers and providers. ${ }^{14}$ This issue is further compounded in nursing home care when social services commissioners lack experience of nursing or health care or access to advice. A third approach is to accept minimum standards enforced by registration officers and to leave quality development to nursing homes and the market, which will reward better homes with a bigger share of what is an increasingly competitive market. Although there is evidence that some homes, particularly the bigger national providers take quality development seriously, there is a concern that this approach will not prevent the recurrent scandals and that with most residents being state funded, tight constraints in central costs will mean that quality is sacrificed to maintain financial returns.

All of this suggests that what is needed is an approach in which registration officers maintain responsibility for external monitoring of minimum standards but additional support for quality improvement through education and development is provided by a district wide team jointly funded through health and social care budgets. This team would need to include geriatricians, social workers, therapists, community nurses and general practitioners. Their role would be to provide clinical support for community based multidisciplinary assessment to a local network of homes and practices, with added responsibility for service coordination and systematic quality review. This would support primary care teams in meeting the needs of their nursing home patients and would allay concerns about 
service fragmentation and variable quality. Care will need to be taken to ensure that the team are not seen as agents of the registration officers, as the other essential component of quality improvement will be the ability of such a team to engage with all homes and to support them and all their staff in adopting internal approaches to quality which they find both enjoyable and rewarding. With appropriate leadership within the homes, this approach is more likely to be sustainable and might result in a virtuous cycle of quality improvement which could even be cost effective, if homes succeeded in reducing their dependence on acute secondary care without detriment to their residents.

CHRIS DRINKWATER

General practitioner, Sir Roy Griffiths-Age Concern-

RCGP Prince of Wales Educational Fellow for Older People

University of Newcastle upon Tyne

Consultant community geriatrician

GABRIELLE C GREVESON

Newcastle City Health NHS Trust

Correspondence to:

Dr Chris Drinkwater, Department of primary care, The Medical

School, Framlington Place, Newcastle upon Tyne NE2 4HH, UK.
1 House of Commons Health Committee. Long-term care: future provision and funding. London: HMSO, 1996.

2 Department of Health, Central Health Monitoring Unit. Health of elderly people: an epidemiological overview. London: HMSO, 1992.

3 Robb B. Sans everything - a case to answer. London: Thomas Nelson, 1967.

4 The NHS and Community Care Act, 1990. London: HMSO, 1990.

5 Alzheimer's Disease Society. Experience of care in residential and nursing homes. London: Alzheimer's Disease Society, 1997.

6 NHS Health Advisory Service. Services for people who are elderly. London: HMSO, 1997.

7 McGrath AM, Jackson G. Neuroleptic prescribing in Glasgow nursing homes. BMF 1996;312:611-2.

8 General Medical Services Committee. Defining core services in general practice-reclaiming professional control. London: BMA, 1996.

9 Dickinson E, Brocklehurst J. Improving the quality of long-term care for older people: lessons from the CARE scheme. Quality in Health Care 1997; 6:160-4.

10 Challiner Y. Quality assurance experiences in two long-term care institutions for the elderly. Quality in Health Care 1997;6:153-9.

11 Chambers R, Knight F, Campbell I. A pilot study of the introduction of audit in nursing homes. Age Ageing 1996;25:465-369.

12 The Registered Homes Act, 1984. London: HMSO, 1984.

13 Grimshaw JM, Russell IT. Achieving health gain through clinical guidelines II: ensuring guidelines change medical practice. Quality in Health Care 1994;3:45-52.

14 Gray JD, Donaldson LJ. Improving the quality of health care through contracting: a study of health authority practice. Quality in Health Care 1996;5:201-5. 